\title{
Evaluating the antibacterial activity of muramyl dipeptide derivatives, retro-tuftsin derivatives, and anthraquinone oligopeptides against a range of pathogenic bacteria*
}

\author{
Magdalena Wysocka', Krystyna Dzierzbicka ${ }^{\circledR}$ and Beata Krawczyk ${ }^{1}$ \\ 'Gdansk University of Technology, Faculty of Chemistry, Department of Molecular Biotechnology and Microbiology, Gdańsk, Poland; 2Gdansk \\ University of Technology, Faculty of Chemistry, Department of Organic Chemistry, Gdańsk, Poland
}

Search for new and efficient antibiotic is crucial because of microbial drug resistance and problems with side effects of the administered medication. In this study, we evaluate the in vitro microbiological activity of muramyl dipeptide derivatives, retro-tuftsin derivatives (i.e., tuftsin with reversed amino acid sequences), and combinations of retro-tuftsin derivatives with substituted anthraquinones. The potency of the investigated derivatives towards methicillin-sensitive Staphylococcus aureus (MSSA), methicillin-resistant Staphylococcus aureus (MRSA), Pseudomonas aeruginosa, Escherichia coli, and Klebsiella pneumoniae ESBL (extended-spectrum $\beta$-lactamases) was compared based on the spectroscopically-measured minimal inhibitory concentrations (MIC values). The bacterial growth have also been studied with different concentrations of compounds. Statistical analysis of the results revealed that certain modifications lead to promising activity against $S$. aureus (anthraquinone analogue - 3c and retro-tuftsin derivative $\mathbf{- 2} \mathbf{2 b}$ ), while other derivatives exhibit activity against $P$. aeruginosa (muramyl dipeptide derivative - $\mathbf{1 d}$ and retro-tuftsin derivative $-\mathbf{2 b}$ ). The obtained results of microbiological activity indicate that the structure of the tested compounds may be the basis for further modifications.

Keywords: MIC, antimicrobial activity, muramyl dipeptide derivatives, analogues of anthraquinones, retro-tuftsin derivatives

Received: 28 June, 2021; revised: 10 August, 2021; accepted: 12 August, 2021; available on-line: 30 August, 2021

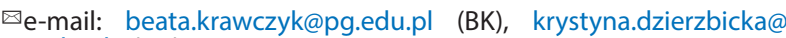
pg.edu.pl; (KD)

*This paper is dedicated to Professor Wacław Tadeusz Szybalski on the 100th anniversary of his birth

Abbreviations: MIC, minimal inhibitory concentration; 1a-e, muramyl dipeptide derivatives; $\mathbf{2 a - 2}$, retro-tuftsin derivatives; $\mathbf{3 a - 3 d}$, anthraquinone derivatives

\section{INTRODUCTION}

The widespread use of classical antibiotics has resulted in the appearance of large numbers of infections caused by organisms that are resistant to the action of one or more of these drugs (Collignon, 2009; Prestinaci et al., 2015). The control of bacteria resistant requires the development of new antimicrobial agents and new knowledge about the use them (Collignon, 2009; Prestinaci et al., 2015).

Among the large group of antibiotics, those containing sugar fragments deserve attention (e.g. aminoglycoside) and peptide antibiotics. Aminoglycoside antibiotics are of particular importance in combating serious infec- tions caused by Gram-negative bacteria, Mycobacterium tuberculosis, Staphylococci and Streptococi (they interact synergistically with $\beta$-lactams by increasing their permeability). The presence of hydroxyl and amino groups in amino sugar molecules determines their biological activity. They have a bactericidal effect, bind to the 30 s subunit of the ribosome, which leads to the disturbance of genetic information reading and inhibition of bacterial protein synthesis (Wright et al., 1998). The advantage of aminoglycoside antibiotics like peptide antibiotics is their natural origin, high microbiological activity and relatively low consumption of compounds in therapy. Antimicrobial peptides (AMPs) discovered in the 1980s represent an alternative to classical antibiotics (Zasloff, 2002). AMPs exist in all kingdoms of life and are the indispensable components of innate immunity in various species including humans, animals, and plants, and represent the first line of defense against infection (Zasloff, 2002; Maróti et al., 2011). The mechanisms of AMP action are different from traditional antibiotics. AMPs display broad-spectrum and potent antimicrobial efficacy against various microbes and even drug-resistant ones (Brogden, 2005). Many natural peptides are effective against strains resistant to conventional antibiotics. The great advantage of peptide antibiotics as opposed to conventional antibiotics is the absence of microbial resistance to these substances. Some antimicrobial peptides have the ability to bind to bacterial lipopolysaccharide, thus preventing the effects of septic shock (Giacometti et al., 2003).

Peptide antibiotics are characterized by high specificity, good solubility and the ability to penetrate the compound to the site of the active. The introduction of cyclic systems or D-amino acids, $\alpha, \beta$-unsaturated, $\alpha$-substituted amino acids reduces the biodegradability of the antibiotic peptide chain.

Most of them are cationic that play a key antimicrobial role (Hancock et al., 1998; Zasloff, 2002; Brogden, 2005; Maróti et al., 2011). An example of a compound containing a sugar fragment and oligopeptide is muramyl dipeptide (MurNAc-L-Ala-D-isoGIn; MDP), a component of peptidoglycan. MDP stimulates various functions of macrophages and increases nonspecific resistance of the host against many microorganisms. The activation of macrophages plays a key role in the infection response mechanism. They take part in the production of microbicidal oxygen radicals and increased secretion of inflammatory cytokines (interleukin-1 and tumor necrosis factor $\alpha$ ). MDP a cytosolic protein NOD2 (nucleotide-binding oligomerization domain-containing protein 2) agonist induces nuclear factor kappa-light-chain-enhancer of activated B cells (NF-kappa B) and mitogen-activated 
protein kinase (MAPK), leading to the production of antimicrobial and proinflammatory substances. Today we can assume that this class of compounds is important as alternative therapeutic agents in the future (Dzierzbicka et al., 2003a, 2011).

Another immunomodulator is the natural tetrapeptide, Thr-Lys-Pro-Arg (TKPR), present in the peripheral blood of humans and other mammals, where it stimulates monocytes, macrophages, and neutrophils (Wardowska et al., 2006; Wardowska et al., 2007; Wardowska et al., 2009; Siebert et al., 2017). Tuftsin supports the introduction of active substances into target cells (particularly macrophages), thus promoting their activation. The placement of tuftsin in liposomes or on the surface of liposomes carrying antibiotics (e.g., amphotericin $\mathrm{B}$ or nystatin) has been shown to increase (i) the specific binding of carriers to the cells of the mononuclear phagocyte system and (ii) the cytotoxic activity of these cells, which ultimately enhances the therapeutic effect of the drug. The effectiveness of antibiotic and tuftsin combination therapy has been confirmed by studies on animal models suffering from bacterial (Gupta \& Haq, 2005), viral (Gupta \& Haq 2005), parasitic (Owais et al., 2003), and fungal diseases (Khan \& Owais, 2005). Besides, feeding animals with tuftsin alone increased their resistance to malaria (Gupta \& Haq, 2005), leishmaniasis (Agrawal et al., 2002), and fungal infections (Khan et al., 2006).

To date, several hundred anthraquinone derivatives have been synthesized (Dzierzbicka \& Kołodziejczyk, 2005a). Most of the anthraquinone modifications aimed at counteracting multi-drug resistance involve a combination with a chromophore with a five- or six-membered heterocyclic ring (e.g., antrapirazoles, antrapiridones, antrapiridazones, benzo[e]pyrimidones). Although a series of anthraquinone analogs have been synthesized previously, and some of them have shown very interesting and promising properties, the search for new analogues (including those capable of operating via a different mechanism from the one previously known) is still ongoing.

In this study, we present the microbiological activity of muramyl dipeptide derivatives $1 \mathrm{a}-\mathrm{e}$, retro-tuftsin (i.e., tuftsin with reversed amino acid sequence) derivatives in the form of trifluoroacetates $2 \mathbf{a}-\mathbf{c}$, and combinations of retro-tuftsin derivatives with anthraquinones 3a-d (Fig. 1). The synthesis of test compounds has been described in our previous publications (Dzierzbicka et al., 2003b; Dzierzbicka et al., 2004; Dzierzbicka et al., 2005b; Dzierzbicka et al., 2006; Dzierzbicka et al., 2008; Dzierzbicka et al., 2012; Kukowska-Kaszuba et al., 2008), and herein, we investigate the antimicrobial activity of the three groups derivatives. It is possible that combining compounds showing different mechanisms of action may improve the clinical properties of both components; therefore, we propose that new analogues of anthraquinones, and muramyl dipeptide derivatives or retro-tuftsin derivatives will exhibit enhanced effectiveness against bacterial infections.

\section{MATERIALS AND METHODS}

\section{Chemical materials}

MDP and nor-MDP derivatives 1a-e (Fig. 1) were prepared and characterized according to previously described methods (Dzierzbicka, 2004; Dzierzbicka \& Kołodziejczyk, 2003b).

The protected retro-tuftsin deratives $2 \mathrm{a}-\mathrm{c}$ (Fig. 1) were prepared using a mixed anhydride method with isobutyl chloroformate and (NMM) in anhydrous N,Ndimethylformamide (DMF). Tert-butyloxycarbonyl (Boc) protecting groups were removed from the peptide with trifluoroacetic acid to give the corresponding trifluoroacetates (Dzierzbicka et al., 2003b; Dzierzbicka et al., 2004; Dzierzbicka et al., 2005b; Dzierzbicka et al., 2008; Kukowska-Kaszuba et al., 2008).

1,4- or 1,8-dihydroxyanthraquinone and para-toluenesulfonyl chloride were used to synthesize 1,4- or 1,8-bis(tosyloxy)anthraquinone. These compounds reacted with an excess of the corresponding retro-tuftsin derivative, TFA $\cdot \operatorname{Arg}\left(\mathrm{NO}_{2}\right)-\operatorname{Pro}-\mathrm{Lys}(\mathrm{Z})-\mathrm{Thr}-\mathrm{OMe}, \mathrm{TFA} \cdot \operatorname{Arg}\left(\mathrm{NO}_{2}\right)-\mathrm{Pro}-$ Lys(ZAla)-Thr-OMe, or TFA.Arg( $\left.\mathrm{NO}_{2}\right)$-Pro-Lys(ZVal)Thr-OMe in the presence of triethylamine (TEA) to afford the monosubstituted derivatives. The protected compounds were treated with liquid hydrogen fluoride (HF) containing anisole at $-70^{\circ} \mathrm{C}$ and stirred for $60 \mathrm{~min}$ at $0^{\circ} \mathrm{C}$. After removal of $\mathrm{HF}$ and anisole in vacuo, the mixture was diluted with acetic acid. The solvent was evaporated under reduced pressure, and the residue was dissolved in water and lyophilized to give compounds $3 a-d$ (Fig. 1) (Dzierzbicka et al., 2012).

\section{Preparing the compounds for testing}

All examined compounds were dissolved in 6\% dimethyl sulfoxide (DMSO; Merck KGaA, Darmstadt, Germany) to prepare stock solutions with concentrations of $10 \mathrm{mg} / \mathrm{mL}$. Serial dilutions were performed until a final concentration of $4096-1 \mu \mathrm{g} / \mathrm{mL}$ was obtained, and these solutions were stored at $-20^{\circ} \mathrm{C}$ until used. The final concentrations of the reference antibiotics solutions were $512-1 \mu \mathrm{g} / \mathrm{mL}$ for kanamycin and tetracycline, and 128$0.25 \mu \mathrm{g} / \mathrm{mL}$ for chloramphenicol.
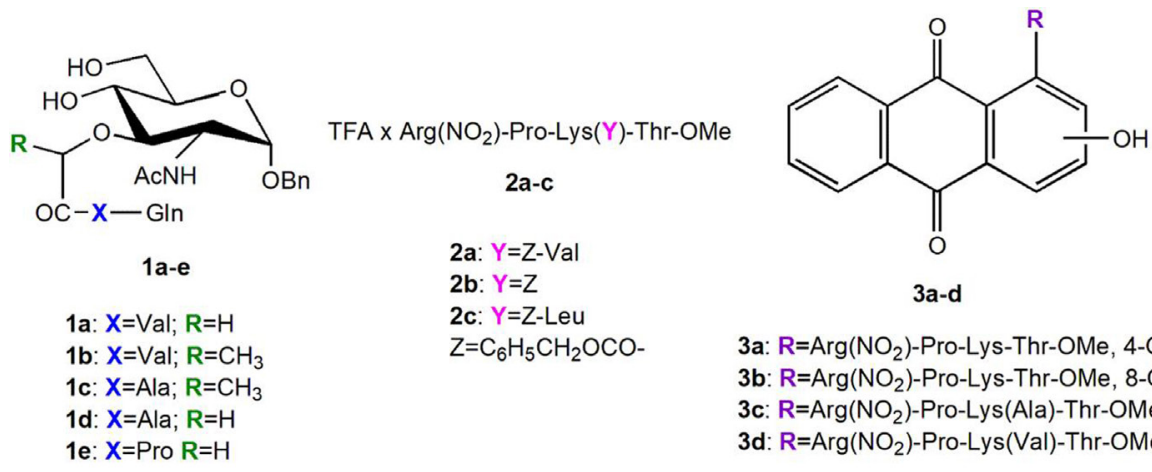

3a: $R=A r g\left(\mathrm{NO}_{2}\right)-$ Pro-Lys-Thr-OMe, $4-\mathrm{OH}$
3b: $\mathrm{R}=\operatorname{Arg}\left(\mathrm{NO}_{2}\right)$-Pro-Lys-Thr-OMe, $8-\mathrm{OH}$
3c: $\mathrm{R}=\operatorname{Arg}\left(\mathrm{NO}_{2}\right)$-Pro-Lys(Ala)-Thr-OMe, $4-\mathrm{OH}$
3d: $\mathbf{R}=\operatorname{Arg}\left(\mathrm{NO}_{2}\right)$-Pro-Lys(Val)-Thr-OMe, $4-\mathrm{OH}$

Figure 1. Structures of tested compounds. 1a-1e, muramyl dipeptide derivatives; 2 a-2c, retro-tuftsin derivatives; $3 a-3 d$, anthraquinone derivatives. 


\section{Bacterial strains and growth conditions}

Antimicrobial susceptibility testing was performed for five reference strains: Klebsiella pneumoniae ATCC 700603 (ESBL); Escherichia coli ATCC 8739; Pseudomonas aeruginosa ATCC 27853; Staphylococcus aureus ATCC 43300 (MRSA); and Staphylococcus aureus ATCC 25923 (MSSA). All strains were grown in Mueller-Hinton 2 Lab Agar (MHA) culture medium (BioMaxima S.A. Poland). Incubation took place aerobically at $37^{\circ} \mathrm{C}$. All plates were incubated for 18-20 h.

Preparation of the bacterial suspension for susceptibility testing The bacterial cell number used for susceptibility testing was standardized according to published procedures (Andrews, 2001; Wiegand et al., 2008; CLSI 2020). Bacteria from four to five colonies with identical morphological appearance were taken from the fresh nutrient-rich MHA plate to prepare overnight cultures. Next, a bacterial suspension with a density equivalent to $10^{8} \mathrm{CFU} / \mathrm{mL}$ was used to inoculate nutrientrich medium MHBII (Mueller-Hinton Broth II; Merck KGaA, Darmstadt, Germany) (volume $4 \mathrm{ml}$ ), and the cultivation was carried out for 4-6 h (depending on the bacterial species). The density of the cell suspension was assessed spectroscopically (PlateReader AF2200 UV/Visible and Fluorescence Microplate Reader (Eppendorf) spectrophotometer; $600 \mathrm{~nm}$ wavelength). After broth dilution of the culture by 1:100, it was used within $30 \mathrm{~min}$ to test the minimum inhibitory concentration (MIC) to avoid changes within the cell number.

Bacterial growth curves The growth rates of the examined strains in the absence and presence of the compounds and antibiotics were determined by introducing a $1 \times 10^{8} \mathrm{CFU} / \mathrm{mL}$ inoculum (volume $1 \mathrm{~mL}$ ) of the starting bacterial culture into a flask containing $50 \mathrm{~mL}$ MHBII and mixing at $120 \mathrm{rpm}$ for $24 \mathrm{~h}$ at $37 \pm 0.1^{\circ} \mathrm{C}$. The dynamics of bacterial growth were evaluated by measuring the absorbance at $600 \mathrm{~nm}\left(\mathrm{OD}_{600}\right)$ wavelength every 2 h, using a PlateReader AF2200 UV/Visible and Fluorescence Microplate Reader (Eppendorf) spectrophotometer.

\section{Antimicrobial susceptibility testing (MIC testing)}

The MICs of the compounds were measured in 96well microtiter plates according to the Clinical and Laboratory Standards Institute (CLSI) guidelines (Methods for Dilution Antimicrobial Susceptibility Tests for Bacteria To Grow Aerobically) (Andrews, 2001; Wiegand et al., 2008; CLSI 2020). All the MIC measurements were carried out in triplicate. Briefly, liquid MHBII medium containing increasing concentrations of compounds and the growth control well were inoculated with $50 \mu \mathrm{L}$ of bacterial suspension in 96-well microtiter polypropylene plates. This leads to the final desired inoculum of $5 \times 10^{5}$ $\mathrm{CFU} / \mathrm{mL}$. Each plate also had a sterility control well containing $100 \mu \mathrm{L}$ of broth.

A $10 \mu \mathrm{L}$ sample from the growth control well was removed immediately after inoculating the plate, and the sample was pipetted into a sterile Eppendorf tube holding $990 \mu \mathrm{L}$ of sterile saline or broth. The tube was mixed well by vortexing. A further dilution of this suspension (1:10) was performed by pipetting $100 \mu \mathrm{L}$ into $900 \mu \mathrm{L}$ of sterile saline or broth and mixed well. Then, $100 \mu \mathrm{L}$ of each of the three dilutions was plated onto three different nutrient-rich agar plates and incubated at $37^{\circ} \mathrm{C}$ for 18-20 h, at which point, the colonies were counted.

All microtiter polypropylene plates were incubated for 18-20 h. After incubation, the MIC was determined based on the lowest concentration showing no visible growth. Evaluation was performed visually and spectroscopically $\left(\mathrm{OD}_{600}\right.$; PlateReader AF2200 UV/VIS and Fluorescence Microplate Reader, Eppendorf). The MICs of the reference antibiotics (kanamycin, tetracycline, and chloramphenicol) were measured in 96-well microtiter plates according to the CLSI (Andrews, 2001; Wiegand et al., 2008; CLSI 2020).

To confirm the results, a resazurin-based assay was also used. Resazurin is a redox indicator used to evaluate cell growth (Elshikh et al., 2016); a pink or uncolored solution indicates growth, and blue indicates inhibition of growth. Resazurin ( $10 \mathrm{~mL}$ of a $0.015 \%$ aqueous solution) was added to each well. Samples were incubated at $37^{\circ} \mathrm{C}$ for $2 \mathrm{~h}$ (in the dark), and then absorbance measurements and visual evaluation of the color relative to the control were performed. The lowest concentration at which the color change occurred was considered the MIC value.

\section{Data analysis}

MIC values were determined in triplicate in three independent experiments for antibiotics, and in duplicate in the three independent experiments for peptides and compounds. The data were collected and evaluated using the R (ver. 3.5.3) (Core Team. 2020) for all calculations and data visualizations.

\section{RESULTS}

\section{Antimicrobial activity of selected antimicrobial compounds}

Twelve antimicrobial components from different classes and origins (Fig. 1) were selected and evaluated concerning their antimicrobial activity, i.e., muramyl dipeptide derivatives $(\mathbf{1} \mathbf{a}-\mathbf{e})$, the retro-tuftsin derivatives $(2 \mathbf{a}-\mathbf{c})$, and analogs of anthraquinones $(3 \mathbf{a}-\mathbf{d})$. These compounds were previously published as potential immunomodulators by Dzierzbicka and others (Dzierzbicka et al., 2003b; Dzierzbicka et al., 2004; Dzierzbicka et al., 2005a; Dzierzbicka et al., 2005b; Dzierzbicka et al., 2006; Dzierzbicka et al., 2008; Dzierzbicka et al., 2012) and Wardowska and others (Wardowska et al., 2006; Wardowska et al., 2009). Their antimicrobial activities were tested against five bacterial strains from four species ( $S$. aureus MRSA/MSSA, $K$. pneumoniae ESBL, $P$. aeruginosa, and E. coli), and their MIC values (and those of the reference antibiotics) are presented in Table 1. The potency of the compounds examined in this study, were compared with the antimicrobial activity of well-characterized antibiotics from different classes, that target bacterial cell walls, proteins, or nucleic acid synthesis ( $\mathrm{Ta}$ ble 1). Muramyl dipeptide derivatives showed the low antimicrobial activities (mostly MIC was $>512 \mu \mathrm{g} / \mathrm{mL}$ ) regardless of the bacterial species (the exception was compound 1d for $P$. aeruginosa). Retro-tuftsin derivatives showed different activities depending on the bacterial species (MIC value from 32 to $512 \mu \mathrm{g} / \mathrm{mL}$ or no inhibitory effect). Anthraquinone analogues were mostly characterized by a lack of antimicrobial activity, except for $\mathbf{3 c}$ and $\mathbf{3 d}$ derivatives. Finally, we found that the derivatives $1 \mathrm{~d}, \mathbf{2 b}$ and $\mathbf{3 c}$ proved to be the most active, hence we focused on these compounds.

In addition to the MIC values, the bacterial growth curves prepared against various concentrations of compounds. At first, the growth curves of bacteria cultured without antibiotics or tested compounds were prepared 
Table 1. Antimicrobial activities (MIC values in $\mu \mathrm{g} / \mathrm{mL}$ ) of various compounds against Gram-negative and Gram-positive bacteria. $\mathrm{NI}$, no inhibitory effect at the compound concentrations used or stimulation of growth; bolded values of MIC mean the most promising compounds.

\begin{tabular}{|c|c|c|c|c|c|c|}
\hline \multirow[b]{2}{*}{$\begin{array}{l}\text { Group of compo- } \\
\text { unds }\end{array}$} & \multirow[b]{2}{*}{$\begin{array}{l}\text { Antimicrobial com- } \\
\text { pounds }\end{array}$} & \multicolumn{5}{|c|}{$\mathrm{MIC}(\mu \mathrm{g} / \mathrm{mL})$} \\
\hline & & $\begin{array}{l}\text { E. coli } \\
\text { ATCC } 8739\end{array}$ & $\begin{array}{l}\text { P. aeruginosa } \\
\text { ATCC } \mathbf{2 7 8 5 3}\end{array}$ & $\begin{array}{l}\text { S. aureus } \\
\text { ATCC } 43300 \\
\text { MRSA }\end{array}$ & $\begin{array}{l}\text { S. aureus } \\
\text { ATCC } 25923 \\
\text { MSSA }\end{array}$ & $\begin{array}{l}\text { K. pneumoniae } \\
\text { ATCC } 700603 \\
\text { ESBL }\end{array}$ \\
\hline \multirow{5}{*}{$\begin{array}{l}\text { muramyl dipeptide } \\
\text { derivatives }\end{array}$} & $1 \mathrm{a}$ & $>512$ & $>512$ & $>512$ & $>512$ & $>512$ \\
\hline & $1 b$ & $>512$ & $>512$ & $>512$ & $>512$ & $>512$ \\
\hline & $1 c$ & $>512$ & $>512$ & $>512$ & $>512$ & $\mathrm{NI}$ \\
\hline & $1 d$ & $>512$ & 128 & $>512$ & $>512$ & $\mathrm{NI}$ \\
\hline & $1 e$ & $>512$ & 512 & $>512$ & $>512$ & $\mathrm{NI}$ \\
\hline \multirow{3}{*}{$\begin{array}{l}\text { retro-tuftsin } \\
\text { derivatives }\end{array}$} & $2 a$ & $>512$ & 256 & $>512$ & 256 & $\mathrm{NI}$ \\
\hline & $2 b$ & $>512$ & 128 & $>512$ & 32 & $\mathrm{NI}$ \\
\hline & $2 c$ & 512 & 256 & $>512$ & $>512$ & $\mathrm{NI}$ \\
\hline \multirow{4}{*}{$\begin{array}{l}\text { anthraquinone } \\
\text { analogues }\end{array}$} & 3a & $\mathrm{NI}$ & $\mathrm{NI}$ & $\mathrm{NI}$ & $\mathrm{NI}$ & $\mathrm{NI}$ \\
\hline & $3 b$ & $\mathrm{NI}$ & $\mathrm{NI}$ & $\mathrm{NI}$ & $\mathrm{NI}$ & $\mathrm{NI}$ \\
\hline & $3 c$ & $\mathrm{NI}$ & $\mathrm{NI}$ & 256 & 256 & $\mathrm{NI}$ \\
\hline & $3 d$ & $\mathrm{NI}$ & $\mathrm{NI}$ & 512 & 512 & $\mathrm{NI}$ \\
\hline \multirow{3}{*}{$\begin{array}{l}\text { reference antibio- } \\
\text { tics }\end{array}$} & kanamycin & 8 & 128 & 64 & 8 & 32 \\
\hline & chloramphenicol & 2 & 64 & 8 & 4 & 16 \\
\hline & tetracycline & $\leq 1$ & 16 & $\leq 1$ & $\leq 1$ & 8 \\
\hline
\end{tabular}

(Fig. S1 at https://ojs.ptbioch.edu.pl/index.php/abp/) in optimal growth conditions.

Figures 2-4 show results of percent of growth of tested bacteria for compounds with a highest potency relative to the control. The effects of chosen compounds $(\mathbf{1 d}, \mathbf{2 b}, \mathbf{3 c})$ and kanamycin, tetracycline, and chloramphenicol on the spectroscopically measured growth of $S$. aureus MRSA, $S$. aureus MSSA and $P$. aeruginosa are presented in Fig. S2, S3, and S4 (at https://ojs.ptbioch. edu.pl/index.php/abp/).

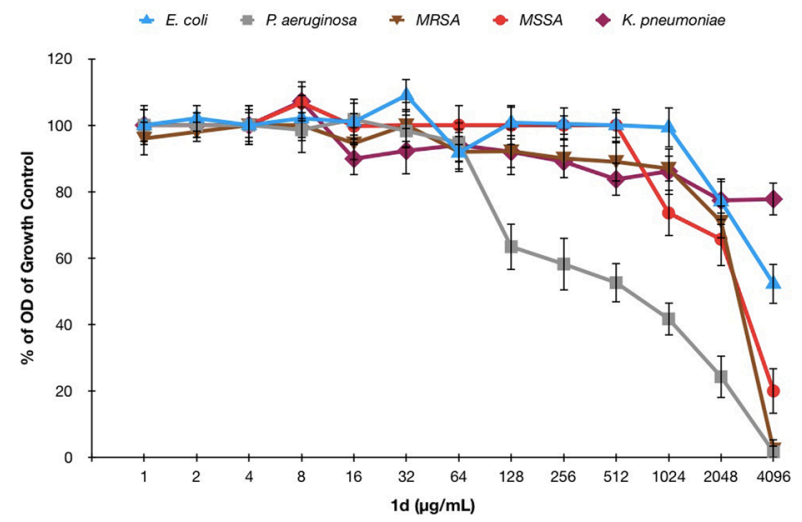

Figure 2. Effect of the muramyl dipeptide derivative 1d on the spectroscopically measured growth of $E$. coli, $P$. aeruginosa, $S$. aureus MRSA, $S$. aureus MSSA, and $K$. pneumoniae ESBL cultured in MHBII medium, compared with the drug-free control well.

The results are presented as the mean of three separate experiments in triplicate, and the error bars represent standard deviation. The MIC values are presented in a logarithmic scale $\left(\log _{2}\right)$.
The MICs was determined for bacterial growth in the range from 30-100\%. Many examined compounds inhibited the growth of microorganisms in $50-100 \%$ only at very high concentrations. The antimicrobial activity of muramyl dipeptide derivatives were generally higher against Gram-negative bacteria compared with Grampositive bacteria. Only 1d demonstrated specific antimicrobial activity against $P$. aeruginosa, whereas the other derivatives were ineffective (MIC $\geq 512 \mu \mathrm{g} / \mathrm{mL}$ ). Compound $1 \mathbf{d}$ inhibited growth by $40 \%$ at a concentration

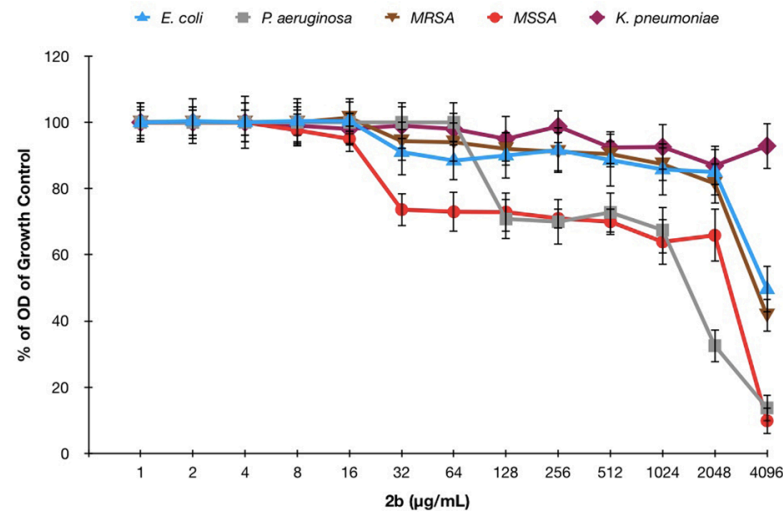

Figure 3. Effect of the retro-tuftsin $\mathbf{2 b}$ derivative on the spectroscopically measured growth of $E$. coli, $P$. aeruginosa, $S$. aureus MRSA, S. aureus MSSA, and K. pneumoniae ESBL cultured in MHBII medium, relative to the drug-free control well.

The results are presented as the mean of three separate experiments in triplicate, and the error bars represent standard deviation. The MIC values are presented in a logarithmic scale $\left(\log _{2}\right)$. 


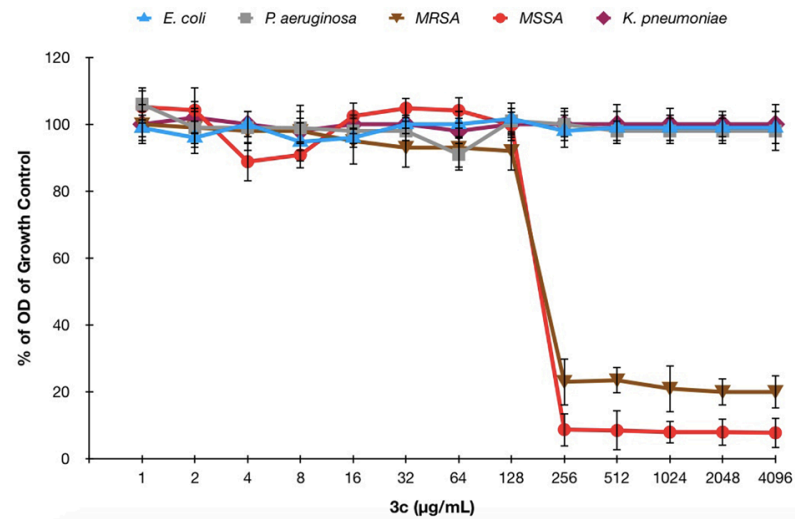

Figure 4. Effect of combining retro-tuftsin derivatives with anthraquinones on the spectroscopically measured growth of $E$. coli, P. aeruginosa, S. aureus MRSA, S. aureus MSSA, and K. pneumoniae cultured in MHBII medium relative to the drug-free control well.

The results are presented as the mean of three separate experiments in triplicate, and the error bars represent standard deviation. The MIC values are presented in a logarithmic scale $\left(\log _{2}\right)$.

of $128 \mu \mathrm{g} / \mathrm{mL}$. The results of the study are shown in Table 1 and Fig. 2 for $1 \mathbf{d}$ derivatives.

The highest antimicrobial activity among retro-tuftsin derivatives was observed for $2 \mathrm{~b}$ against $P$. aeruginosa and S. aureus ATCC25923 (MSSA), which inhibited their growth by $30 \%$ at concentrations of $128 \mu \mathrm{g} / \mathrm{mL}$ and $32 \mu \mathrm{g} / \mathrm{mL}$, respectively. The second most effective compound (MIC $256 \mu \mathrm{g} / \mathrm{mL}$ ) was $2 \mathrm{a}$ against $S$. aureus and $P$. aeruginosa. In fact, 2 a displayed the same high specific activity against $P$. aeruginosa as 2 c. Antimicrobial activities for retro-tuftsin derivatives are included in Table 1. Effect of the retro-tuftsin $2 \mathbf{b}$ derivative on the spectroscopically measured growth of bacteria is shown in Fig. 3.

Among the anthraquinone analogs (retro-tuftsin derivatives with anthraquinones), only $3 c$ exhibited specific antimicrobial activity against $S$. aureus, whereas no activity was detected against any of the Gram-negative bacteria tested ( $K$. pneumoniae, E. coli, P. aeruginosa) (Fig. 4). At a concentration of $256 \mu \mathrm{g} / \mathrm{mL}, 3 \mathbf{c}$ inhibited the growth of MSSA and MRSA by $90 \%$ and $80 \%$, respectively. Among the other anthraquinone analogs, 3d was slightly less active against Gram-positive pathogens, and no activity was detected against Gram-negative bacteria (Fig. 4).

\section{DISCUSSION}

The high activity of antibiotics toward pathogenic bacteria provides a wide range of possibilities for their use in medicine. However, antibiotics and microbial resistance limit the effectiveness of currently used antibiotics and highlight the need for antibiotic compounds with unique chemical structures. The constant need for new, synthetic, more effective antibiotics stimulates research in this area. In this work, we obtained compounds derived from natural immunomodulators (e.g., peptidoglycan of the bacterial cell wall - muramyl peptides for 1a-c compounds) or fragments of immunoglobulins (tuftsin for $2 \mathrm{a}-\mathrm{c}$ and $3 \mathrm{a}-\mathrm{d}$ compounds) and explored their potential antimicrobial activities.

Compounds composed of sugar and oligopeptide (e.g., MDPs) can increase the non-specific (natural) re- sistance of higher organisms to bacterial infections. This phenomenon was first described by Chedid and others (Chedid et al., 1977), who demonstrated that MDP administered intravenously, subcutaneously, or even orally reduced the mortality of mice infected the day later with a lethal dose of $K$. pneumoniae. MDP and its analogs can stimulate the non-specific immunity of various animals to infections caused by bacteria, including Mycobacterium tuberculosis, Listeria monocytogenes, $P$. aeruginosa, E. coli, S. aureus, and Streptococcus pneumoniae (Chedid et al., 1978; Fraser-Smith et al., 1982; Humphers et al., 1980; Masihi et al., 1985; Matsumoti et al., 1981; Osada et al., 1982).

Tuftsin is a natural peptide with antibacterial activity. It has been reported that the antimicrobial activity of tuftsin is enhanced by attaching an ethylenediamine fragment to its C-terminus with an acyl residue of fatty acid (e.g., palmitic), and including this modified tuftsin (palmitoyl tuftsin; TKPR-NH- $\left.\left(\mathrm{CH}_{2}\right)_{2}-\mathrm{NH}-\mathrm{CO}-\mathrm{C}_{15} \mathrm{H}_{31}\right)$ in liposomes (Agrawal et al., 2002; Siebert et al., 2017). The tetrameric tuftsin derivative [TKPKG] $]_{4}$ (OT20) was used as a carrier for the peptide molecule, TB5 (Horvati et al., 2012). A palmitoylated tuftsin derivative (a sequence of TKPKG) of isoniazid (INH) was presented as a potential antitubercular agent (Horvati et al., 2014). Tuftsin with liposomal nystatin increased its activity against Cryptococcus (Khan et al., 2012). Because of the receptors on macrophages, liposomal tuftsin can act as a transporter for the site-specific delivery of drugs in a variety of macrophage-based infections, such as tuberculosis and leishmaniasis (Gupta \& Haq, 2005).

In this study, we also investigated tuftsin derivatives containing anthraquinones with different substituents (3a-d derivatives). Anthraquinones exhibit bactericidal and bacteriostatic properties against both Gram-positive and Gram-negative bacteria (Bashir et al., 2011) (e.g., E. coli, Mycobacterium smegmatis, K. pneumoniae, Enterococcus faecalis, Bacillus subtilis, S. aureus, Staphylococcus epidermidis, Helicobacter pylori, P. aeruginosa, and Salmonella Typhimurium (Alemdar \& Agaoglu, 2009; Alves et al., 2004; Antonisamy et al., 2012; Chung et al., 1997). They are also potent bacteriostatic agents against Streptococcus viridans and Streptococcus mutans (Coenye et al., 2007). The antibacterial properties of anthraquinones can be applied in medicine, especially since one of the worrying problems is the constantly growing multidrug resistance of microorganisms to antibiotics. However, compounds with immunomodulatory activity are not necessarily effective chemotherapeutic agents. Therefore, conjugates that exhibit simultaneous immunomodulatory and antimicrobial activity would be the best option.

\section{Antimicrobial activity of selected antimicrobial compounds}

Currently growing numbers of antibiotic-resistant pathogens, and the capacity of available antimicrobial compounds to control bacterial infections is declining. The selected microorganisms quickly develop resistance to various classes of antibiotics via mutations or horizontal gene transfer (HGT). Extended-spectrum $\beta$-lactamase (ESBL)-producing $K$. pneumoniae is an example of bacteria with resistance to all penicillins and cephalosporins. MRSA strains are associated with resistance to most semisynthetic penicillins. Similarly, $P$. aeruginosa and E. coli are resistant to a vast range of antibiotics in hospital environments. Therefore, it is crucial to find new antimicrobial compounds.

Antimicrobial derivatives such as MDPs, retro-tuftsins, or anthraquinones are expected to represent potential al- 
ternatives to classical antibiotics in terms of controlling and combating bacterial infections. Modifying known compounds for further development toward practical applications remains a challenge.

By comparing different compounds using the same assay conditions, this study allows a direct comparison of the antimicrobial activity of an array of compounds against a broader range of bacteria. We found that retrotuftsin derivatives with anthraquinones (3c and $\mathbf{3 d}$ ) displayed potent efficacy against $S$. aureus. This is particularly crucial because the problems associated with both community-associated and hospital-acquired MRSA (CAMRSA and HA-MRSA, respectively) are increasing (Kateete et al., 2019). The biological effect of $\mathbf{3} \mathbf{c}$ and $\mathbf{3 d}$ may be influenced by the presence of isopeptide bonds in the peptide chain (retro-tuftsin). Replacement of the protonated $\varepsilon$-amino group of lysine with an electrically neutral amide bond reduces the susceptibility to enzymatic hydrolysis, and thus reduces the inhibitory effect of the resulting degradation products.

Retro-tuftsin derivatives $2 \mathrm{a}-\mathrm{c}$ seem to exhibit suitable activity against MSSA strains but not MRSA strains. However, the effects of $2 \mathrm{a}-\mathrm{c}$ against $P$. aeruginosa was significant and similar to the MDP derivative, 1d. This was an important observation because $P$. aeruginosa poses many serious threats (McGowan, 2006) in terms of nosocomial (hospital-acquired) infections, which occur mainly in patients from high-risk groups, but they rarely cause community-acquired infections.

In particular, $P$. aeruginosa is often responsible for nosocomial infection in patients with burns and other wounds, and the $P$. aeruginosa strains are characterized by high inherent resistance and the ability to develop new mechanisms of antibiotic resistance. The diversity of resistance mechanisms in $P$. aeruginosa makes them especially difficult to eradicate from hospital environments. The new muramyl dipeptide derivative (1d) and retrotuftsin derivatives $(\mathbf{2 a - c})$ have the potential for inducing antibacterial activity, especially against $P$. aeruginosa.

\section{CONCLUSIONS}

In this work, 12 new compounds (previously characterized) were tested toward five different bacterial cell lines. Analysis of the results led to the conclusion that some structurally modified compounds, such as anthraquinone analogue $3 c$ and retro-tuftsin derivative $2 b$, show promising activity against $S$. aureus, while MDP derivative $\mathbf{1 d}$ and retro-tuftsins derivative $\mathbf{2 b}$ demonstrate promising activity against $P$. aeruginosa. The results presented herein confirm that structural modifications of anthraquinones and retro-tuftsin can be introduced in order to impart antimicrobial properties.

\section{DECLARATIONS}

\section{Funding}

This research received no external funding

\section{Conflicts of interest}

The authors declare no conflict of interest

\section{Availability of data and material}

Not applicable

\section{Ethics approval}

Not applicable.

\section{Authors' Contribution}

Conceptualization, BK., KD; Methodology, MW., BK; Validation, MW; Software, MW; Formal Analysis, MW., BK., KD; Investigation, MW., BK; Resources, KD, BK; Data Curation, MW., BK; Writing - Original Draft Preparation, MW., BK., KD; Writing - Review \& Editing, BK., KD; Visualization, MW; Project Administration, BK; Funding Acquisition, BK., KD.

\section{REFERENCES}

Agrawal AK, Agrawal A, Pal A, Guru PY, Gupta CM (2002) Superior chemotherapeutic efficacy of amphotericin B in tuftsin-bearing liposomes against Leishmania donovani infection in hamsters. J Drug Target 10: 41-45. https://doi.org/10.1080/10611860290007513

Alemdar S, Agaoglu S (2009) Investigation of in vitro antimicrobial activity of aloe vera Juice. Asian J Anim Vet Adv 8: 99-102

Alves DS, Pe'rez-Fons L, Estepa A, Micol V (2004) Membrane-related effects underlying the biological activity of the anthraquinones emodin and barbaloin. Biochemical Pharmacol 68: 549-561. https://doi. org/10.1016/j.bcp.2004.04.012

Andrews JM (2001) Determination of minimum inhibitory concentrations. J Antimicrob Chemother 48 (Suppl 1): 5-16. https://doi. org/10.1093/jac/48.suppl_1.5

Antonisamy MA, Renisheya Joy Jeba Malar T, Johnson M, Nancy Beaulah S, Laju RS, Anupriya G, Renola Joy Jeba Ethal T (2012) Anti-bacterial and antifungal activity of aloe vera gel extract. Int. J Biomed Adv Res 03: 184-187. https://doi.org/10.7439/ijbar.v3i3.294

Bashir A, Saeed B, Mujahid TY, Jehan N (2011) Comparative study of antimicrobial activities of Aloe vera extracts and antibiotics against isolates from skin infections. African J Biotechnol 10: 3835-3840

Brogden KA (2005) Antimicrobial peptides: pore formers or metabolic inhibitors in bacteria? Nat Rev Microbiol 3: 238-250. https://doi. org/10.1038/nrmicro1098

Chedid L, Audibert F, Johnson A (1978) Biological activities of muramyl dipeptide, a synthetic glycopeptide analogues to bacterial immunoregulating agents. Prog Allergy 25: 63-105

Chedid L, Audibert F, Lefrancier P, Choay J, Lederer E (1977) Enhancement of nonspecific immunity to Kebsiella pneumoniae infection by a synthetic immunoadjuvant ( $N$-acetyl-muramyl-L-alanyl-D-isoglutamine) and several analogs. Proc Natl Acad Sci U S A 74: 20892093. https://doi.org/10.1073/pnas.74.5.2089

Chung JG, Wang HH, Wu LT, Chang SS, Chang WC (1997) Inhibitory actions of emodin on arylamine $N$-acetyltransferase activity in strains of Helicobacter pylori from peptic ulcer patients. Food Chem Toxicol 35: 1001-1007. https://doi.org/10.1016/s0278-6915(97)87269-9

CLSI (2020) Performance Standards for Antimicrobial Susceptibility Testing. 30th edn. CLSI supplement M100. Wayne PA: Clinical and Laboratory Standards Institute

Coenye T, Honraet K, Rigole P, Jimenez PN, Nelis HJ (2007) In Vitro inhibition of Streptococcus mutans biofilm formation on hydroxyapatite by subinhibitory concentrations of anthraquinones. Antimicrob Agents Chemother 51: 1541-1544. https://doi.org/10.1128/AAC.00999-06

Collignon P, Powers JH, Chiller TM, Aidara-Kane A, Aarestrup FM (2009) World Health Organization ranking of antimicrobials according to their importance in human medicine: A critical step for developing risk management strategies for the use of antimicrobials in food production animals. Clin Infect Dis 49: 132-141. https://doi. org/10.1086/599374

Core Team. R: A language and environment for statistical computing. R Foundation for Statistical Computing. (2020) Vienna, Austria. https://www.R-project.org/

Dzierzbicka K (2004) Synthesis of conjugates of muramyl dipeptide and nor-muramyl dipeptide with retro-tuftsin (Arg-Pro-LysThrOMe) as potential immunostimulants. Pol J Chem 78: 409-416

Dzierzbicka K (2008) Synthesis of new conjugates of MDP and norMDP with retro-tuftsin derivatives as potential immunomodulators. Pol J Chem 82: 1431-1439

Dzierzbicka K, Kołodziejczyk AM (2003a) Muramyl peptides - synthesis and biological activity. Pol J Chem 77: 373-395

Dzierzbicka K, Kołodziejczyk AM (2003b) Synthesis and antitumor activity of conjugates of muramyldipeptide or normuramyldipeptide with hydroxyacridine/acridone derivatives. J Med Chem 46: 183-189. https://doi.org/10.1021/jm020991m

Dzierzbicka K, Kołodziejczyk AM (2005a) Anthracenedione analogues - synthesis and biological activity. Pol J Chem 79:1-29

Dzierzbicka K, Sowiński P, Kołodziejczyk AM (2006) Synthesis of analogues of anthraquinones linked to tuftsin or retro-tuftsin resi- 
dues as potential topoisomerase inhibitors. I Pept Sci 12: 670-678. https://doi.org/10.1002/psc.777

Dzierzbicka K, Trzonkowski P, Sewerynek P, Kołodziejczyk AM, Mysliwski A (2005b) Synthesis and biological activity of tuftsin, its analogue and conjugates containing muramyl dipeptides or nor-muramyl dipeptides. I Peptide Sci 11: 123-135

Dzierzbicka K, Wardowska A, Rogalska M, Trzonkowski P (2012) New conjugates of muramyl dipeptide and nor-muramyl dipeptide linked to tuftsin and retro-tuftsin derivatives significantly influence their biological activity. Pharmacological Rep 64: 217-223. https://doi. org/10.1016/s1734-1140(12)70749-1

Dzierzbicka K, Wardowska A, Trzonkowski P (2011) Recent developments in the synthesis and biological activity of muramylpeptides. Curr Med Chem 18: 2438-2451. https://doi. org/10.2174/092986711795843173

Elshikh M, Ahmed S, Funston S, Dunlop S, McGaw M, Marchant R, Banat IM (2016) Resazurin-based 96-well plate microdilution method for the determination of minimum inhibitory concentration of biosurfactants. Biotechnol Lett 38: 1015e1019. https://doi. org/10.1007/s10529-016-2079-2

Fraser-Smith E, Waters R, Matthews T (1982) Correlation between in vivo anti-Pseudomonas and anti-Candida activities and clearance of carbon by the reticuloendothelial system for various muramyl dipeptide analogs, using normal and immunosuppressed mice. Infect Immun 35: 105-110. https://doi.org/10.1128/iai.35.1.105-110.1982

Giacometti A, Cirioni O, Ghiselli R, Orlando F, Mocchegiani F, D'amato G, Silvestri C, Riva A, Del Prete MS, Saba V, Scalise G (2003) Antiendotoxin activity of antimicrobial peptides and glycopeptides. I Chemother 15: 129-133. https://doi.org/10.1179/ joc.2003.15.2.129

Gupta CM, Haq W (2005) Tuftsin-bearing liposomes as antibiotic cariers in treatment of macrophage infections. Methods Ensymol 391: 291-304. https://doi.org/10.1016/S0076-6879(05)91016-1

Hancock REW, Lehrer R (1998) Cationic peptides: A new source of antibiotics. Trends Biotechnol 16: 82-88. https://doi.org/10.1016/ s0167-7799(97)01156-6

Horvati K, Bacsa B, Kiss E, Gyulai G, Fodor K, Balka G, Rusvai M, Szabo N, Hudecz F, Bosze S (2014) Nanoparticle encapsulated lipopetide conjugate of antitubercular drug isoniazid: in vitro intracellular activity and in vivo efficacy in a guinea pig model of tuberculosis. Bioconjug. Chem 25: 2260-2268. https://doi.org/10.1021/bc500476x

Horvati K, Bacsa B, Szabo N, David S, Mezo G, Grolmasz V, Vertessy B, Hudecz F, Bosze S (2012) Enhanced sellular uptake of a new, in silico identified antitubercular candidate by peptide conjugation. Bioconjug Chem 23: 900-907. https://doi.org/10.1021/bc200221t

Humphers R, Henika P, Ferraresi R, Krahenbuhl J (1980) Effects of treatment of muramyl dipeptide and certain of its analogs on resistance to Listeria monocytogenes in mice. Infect Immun 30: 462-466. https://doi.org/10.1128/iai.30.2.462-466.1980

Kateete DP, Bwanga F, Seni J, Mayanja R, Kigozi E, Mujuni B, Ashaba FK, Baluku H, Najjuka CF, Källander K, Rutebemberwa E, Asiimwe BB, Joloba ML (2019) CA-MRSA and HA-MRSA coexist in community and hospital settings in Uganda. Antimicrob Res Infect Control 8: 1-9. https://doi.org/10.1186/s13756-019-0551-1

Khan MA, Aljarbou A, Khan A, Owais M (2012) Immune stimulating and therapeutic potential of tuftsin-incorporated nystatin liposomes against Cryptococcus neoformans in leukopenic BALB/C mice. FEMS Immuno Med Microbiol 66: 88-97. https://doi.org/10.1111/j.1574695X.2012.00992.x
Khan MA, Khan A, Owais M (2006) Prophylactic use of liposomized tuftsin enhances the susceptibility of Candida albicans to fluconazole in leukopenic mice. FEMS Immunol Med Microbiol 46: 63-69. https://doi.org/10.1111/j.1574-695X.2005.00014.x

Khan MA, Owais M (2005) Immunomodulator tuftsin increases the susceptibility of Cryptococucus neoformans to liposomal amphotericin $\mathrm{B}$ in immunocompetent BALB/c mice. J Drug Target 13: 423-429. https://doi.org/10.1080/10611860500403222

Kukowska-Kaszuba M, Dzierzbicka K, Mackiewicz Z (2008) Synthesis of linear tuftsin analogues modified at the e-amino group of lysine. Tetrahedron Lett 48: 5718-5720

McGowan JE Jr (2006) Resistance in nonfermenting Gram-negative bacteria: multidrug resistance to the maximum. Am J Med 119 (6 Suppl 1): S29-S36. https://doi.org/10.1016/j.amjmed.2006.03.014

Maróti G, Kereszt A, Kondorosi É, Mergaert P (2011) Natural roles of antimicrobial peptides in microbes, plants and animals. Res Microbiol. 162: 363-374. https://doi.org/10.1016/j.resmic.2011.02.005

Masihi K, Brehmer W, Lange W, Werner H, Ribi E (1985) Trehalose dimycolate from various Mycobacterial species induces differing anti-infectious activities in combination with muramyl dipeptide. Infection Immun 50: 938-940. https://doi.org/10.1128/iai.50.3.938940.1985

Matsumoto K, Ogawa H, Nagase O, Kusama T, Azuma I (1981) Stimulation of nonspecific host resistance to infection induced by muramyldipeptides. Microbiol Immunol 25: 1047-1058

Osada Y, Mitsuyama M, Matsumoto K, Une T, Otani T, Ogawa H, Nomoto K (1982) Stimulation of resistance of immunocompromised mice by a muramyl dipeptide analog. Infect Immun 37: 12851288. https://doi.org/10.1128/iai.37.3.1285-1288.1982

Owais M, Misra-Bhattacharya S, Haq W, Gupta CM (2003) Immunomodulator tuftsin augments antifilarial activity of diethylcarbamazine against experimental brugian filariasis. J Drug Target 11: 247251. https://doi.org/10.1080/10611860310001620707

Prestinaci F, Pezzotti P, Pantosti A (2015) Antimicrobial resistance: a global multifaceted phenomenon. Pathog Glob Health. 109: 309-318. https://doi.org/10.1179/2047773215Y.0000000030

Siebert A, Gensicka-Kowalewska M, Cholewinski G, Dzierzbicka K (2017) Tuftsin - Properties and analogs. Curr Med Chem 24: 37113727. https://doi.org/10.2174/0929867324666170725140826

Wardowska A, Dzierzbicka K, Mysliwski A (2007) Tuftsin -new analogues and properties. Post Biochem 53:60-65

Wardowska A, Dzierzbicka K, Szarynska M, Dabrowska-Szponar M, Wisniewska K, Mysliwski A, Trzonkowski P (2009) Analogues of muramyl dipeptide (MDP) and tuftsin limit infection and inflammation in murine model of sepsis. Vaccine 27: 369-374. https://doi. org/10.1016/j.vaccine.2008.11.017

Wardowska A, Dzierzbicka K, Trzonkowski P, Mysliwski A (2006) Immunomodulatory properties of new conjugates of muramyl dipeptide and nor-muramyl dipeptide with retro-tuftsin (Arg-Pro-Lys-ThrOMe). Int Immunopharmacol 6: 1560-1568. https://doi.org/10.1016/j. intimp.2006.05.004

Wiegand I, Hilpert K, Hancock REW (2008) Agar and broth dilution methods to determine the minimal inhibitory concentration (MIC) of antimicrobial substances. Nature Protocol 3: 163-175. https://doi. org/10.1038/nprot.2007.521

Wright GD, Berghuis AM, Mobashery S (1998) Aminoglycoside Antibiotics: Structure, Functions and Resistance. Rosen BP, Mabashery $\mathrm{S}$ eds. Plenum Press, New York

Zasloff M (2002) Antimicrobial peptides of multicellular organisms. Nature 415: 389-395. https://doi.org/10.1038/415389a 